\title{
Full factorial DOE to determine the influence of the process parameters in cleaning water jets used in sewer cleaning
}

\author{
Nicolae Medan ${ }^{1, *}$, Mircea Lobontiu $^{1}$, and Mihai Banica ${ }^{1}$ \\ ${ }^{1}$ Technical University of Cluj Napoca, North University Center Baia Mare, 62A, Dr. Victor Babes \\ Street, 430083 Baia Mare, Romania
}

\begin{abstract}
Industrial cleaning is a classic application of water jets technology. In the late 1950s, when reliable high pressure pumps were built, the usage of water jets spread widely in the field of pipes and sewerage cleaning. In our particular case, water jets using pressure between 100 and 200 bars are being used. The operational behaviour of these systems is dependent on the process parameters, which can vary, causing variations in the impact force. The experiment consists in the research method used in the study of the impact forces that occur in the sewerage cleaning head system. To determine the influence process parameters have on impact forces, the full factorial method was used. In order to measure the impact forces between the water jet and a flat and rigid surface, a stand was designed and built for generating pressure water jets, as well as a device to measure the impact forces.
\end{abstract}

\section{Introduction}

Phenomena that occur in the cleaning water jets are complex. Adler [1] describes mechanisms occurring at the impact of a jet with a surface. Leach et al [2], Leu et al [3] and Guha et al [4] analysed pressure distribution along the centreline of the water jet. A number of papers have studied the influence of nozzle geometry on water jet [5-7].

The aim of this paper is to determine the influence of process parameters on impact forces produced by water jets from the sewerage system cleaning head, impact forces that depend on the process parameters. In order to measure the impact forces between the water jet and a flat and rigid surface, a stand for generating pressure water jets, as well as a device to measure the impact forces have been designed and built. In the measurements, water jets using pressure between 100 and 200 bars have been used. The values of these pressures correspond to low pressure water jets [8].

To carry out an experimental research, it is recommended to follow a series of steps [9]: 1) recognition of and statement of the problem, 2) selection of the response variable, 3 ) choice of factors (process parameters), levels, and ranges, 4) choice of experimental design, 5) performing the experiment, 6) statistical analysis of the data, 7) conclusions and recommendations.

\footnotetext{
* Corresponding author: Nicolae.Medan@cunbm.utcluj.ro
} 
To determine the influence of process parameters on impact forces produced by water jets from the sewerage system cleaning head the research method used is full factorial method.

\section{Apparatus used and methodology of the measurements}

In order to measure the impact forces between the water jet and a flat and rigid surface, a stand for generating pressure water jets, as well as a device to measure the impact forces were designed and built [10].

\subsection{The stand to generate pressure water jet}

Schematic diagram of the stand to generate a pressure jet is shown in figure 1 .

The component parts of the stand are: 1) electric motor 2) flexible coupling; 3) high pressure pump, 4) pressure regulator, 5) pressure gauge, 6) nozzle, 7) tap water, 8) water tank, 9) chassis.

Water coming out of the high pressure pump (3) goes into the pressure regulator (4). The pressure regulator adjusts the pressure and flow of the water in the path of the high pressure water. This pressure corresponds to the one at the outlet of the nozzle.

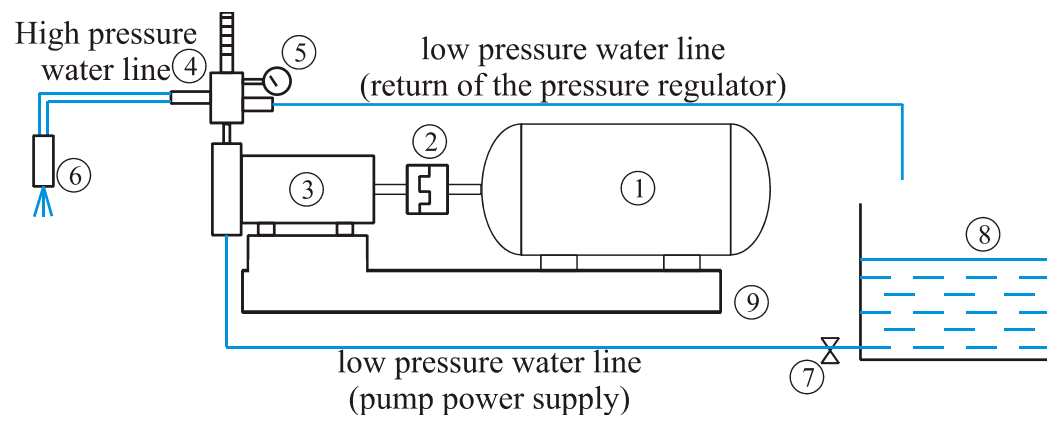

Fig. 1. Schematic diagram of the stand to generate pressure jet.

\subsection{The device to measure the impact forces}

Figure 2 represents the principle diagram of the device for the measurement of the impact force between the water jet and a flat and rigid surface.

The main component parts of the device are:1) high-pressure water hose, 2) support nozzle, 3) nozzle block, 4) nozzle, 5) water jet, 6) flat and rigid target plate, 7) collection path water, 8) scaled container, 9) piezoelectric sensor mounting, 10) piezoelectric sensor, 11) data acquisition Personal Daq/3000, 12) computer for the processing of data; 13) support plate, 14) acrylic tube, 15) rods for adjusting distance $\mathrm{x}$.

From the high pressure water hose (1) the water comes at a certain pressure $\mathrm{p}$ desired. A water jet is generated at the outlet of the nozzle (5) that strikes the target plate (6), which it located at a certain distance $\mathrm{x}$ in front of the nozzle. The jet (5) generates an impact force at a time when it meets the target plate (6). This force produces axial movement of the target plate. This movement is converted into an electric signal by the piezoelectric sensor (10). Electrical signals are collected by data acquisition Personal Daq/3000 (11), which forwards data to a computer (12) using DaqView soft processes. Thus, accurate data is obtained. 


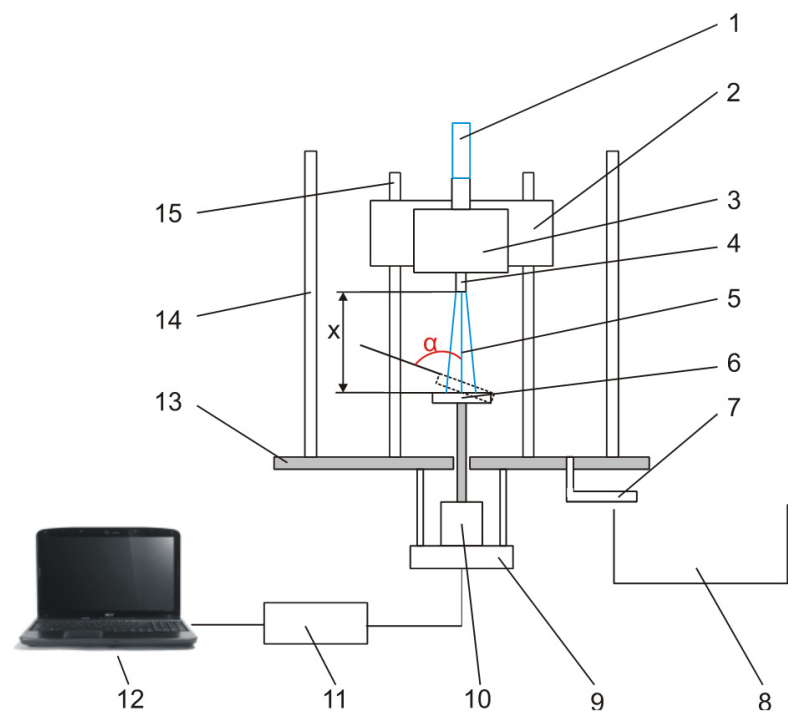

Fig. 2. Diagram of the device for the measurement of the impact force of the water jet.

\subsection{Process parameters and geometric configuration of nozzles}

In the water jet cleaning process a series of parameters are involved [8]. These parameters can be divided into two major groups, namely: 1) target parameters which shall be defined according to the contact area between the water jet and the surface to be cleaned and 2) process parameters. In the measurement of the impact forces of a stationary water jet and flat and rigid surface the process parameters are involved (figure 3 ).

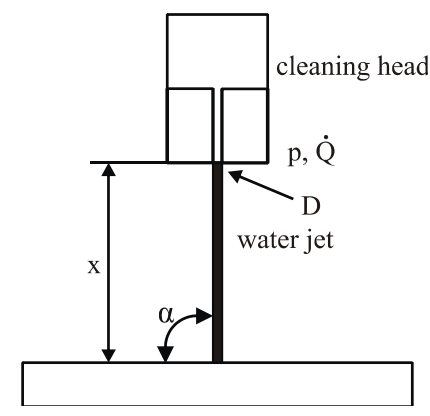

Fig. 3. Process parameters.

They can be divided into two groups, namely hydraulic parameters and the performance parameters. Hydraulic parameters characterized by the system's high pressure pump-nozzle are represented by work pressure (p), volume flow $(\dot{Q})$ and nozzle diameter (D). The performance parameters are more related to the process performance and include the following: cleaning distance $(\mathrm{x})$, impact angle $(\alpha)$ and traverse rate $\left(\mathrm{v}_{\mathrm{T}}\right)$. For a stationary water jet $\mathrm{v}_{\mathrm{T}}=0 \mathrm{~m} / \mathrm{s}$.

Setting the values of process parameters, as follows:

1)The diameter $D$ of the nozzle. The values used are $D=1 \mathrm{~mm}, 1.5 \mathrm{~mm}$ and $2 \mathrm{~mm}$. These are common values used in equipment designed for maintenance and cleaning of sewers. The material used for the nozzles is stainless steel. Figure 4 shows the geometric configuration of the nozzles used. 


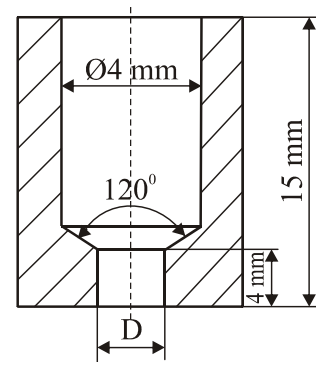

Fig. 4. Geometric configuration of the nozzles.

2)The pressures $p$ used to perform the measurements have the values $p=100$ bar, $p=120$ bar, $p=140$ bar, $p=160$ bar, $p=180$ bar and $p=200$ bar. For the maintenance sewers, maximum pressure used are 200 bars to prevent the damage of the sewer pipe.

3)Cleaning distance $\mathrm{x}$ (distance from the nozzle to the target plate). Distance $\mathrm{x}$ has been fixed at the values from $x=25 \mathrm{~mm}$ to $\mathrm{x}=200 \mathrm{~mm}$, with a step of $25 \mathrm{~mm}$.

4) $\alpha$ - impact angle (the angle formed by the jet with the target plate); in this work $\alpha=60^{\circ}, 75^{\circ}$ and $90^{\circ}$. For cleaning heads the usual value of the angle of impact $\alpha$ is $75^{\circ}$. If impact angle $\alpha$ decreases below $60^{\circ}$ it leads to a drop in of the impact forces.

\section{Results}

For determining the influence of the process parameters the method used shall be full factorial design.

\subsection{Choice of levels and values for process parameters}

Table 1 presents the values of the parameters used for full factorial method.

Table 1. The values of the parameters.

\begin{tabular}{|c|c|}
\hline Parameter & Values \\
\hline Nozzle diameter D $[\mathrm{mm}]$ & $1,1.5,2$ \\
\hline Pressure $\mathrm{p}[\mathrm{bar}]$ & $100,120,140,160,180,200$ \\
\hline Impact angle $\alpha\left[^{0}\right]$ & $60,75,90$ \\
\hline Distance $\mathrm{x}[\mathrm{mm}]$ & $25,50,75,100,125,150,175,200$ \\
\hline
\end{tabular}

\subsection{Performing the experiment}

Taking into account that there are four parameters, the number of values which they each take and using the Full factorial design results in a number of 144 experiments. For each experiment three measures of impact force were performed and still it has worked with $\mathrm{F}_{\text {med, }}$, representing the arithmetic average of the three forces measured. As a result there are a number of 432 measurements. With this in mind, for the brief of this paper, we dare not present the table with the values obtained.

Based on the values of impact forces obtained using the full factorial method, figures 5 , 6 and 7 present the values of impact forces $F_{\text {med }}$ which depend on process parameters (values of process parameters presented in table 1). 


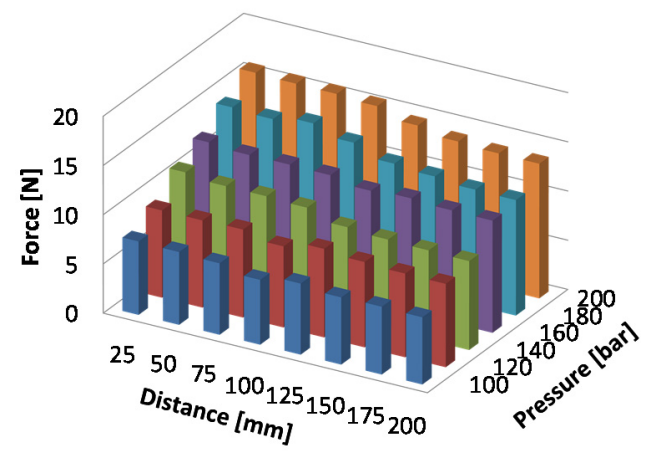

c) $\alpha=60^{0}$

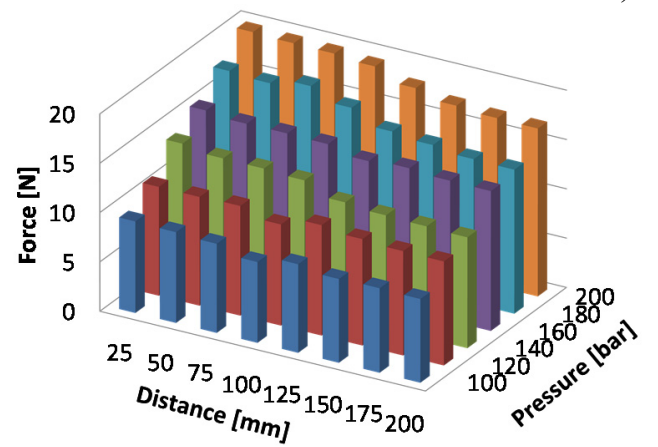

a) $\alpha=90^{\circ}$

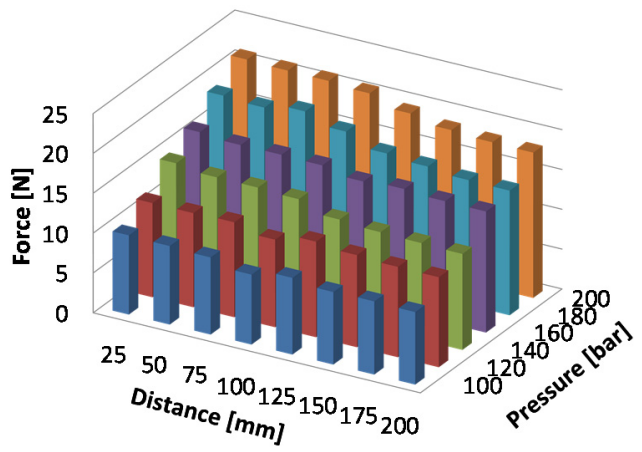

b) $\alpha=75^{0}$

Fig. 5. Values of impact forces for nozzle diameter $\mathrm{D}=1 \mathrm{~mm}$ for different values of impact angle $\alpha$.

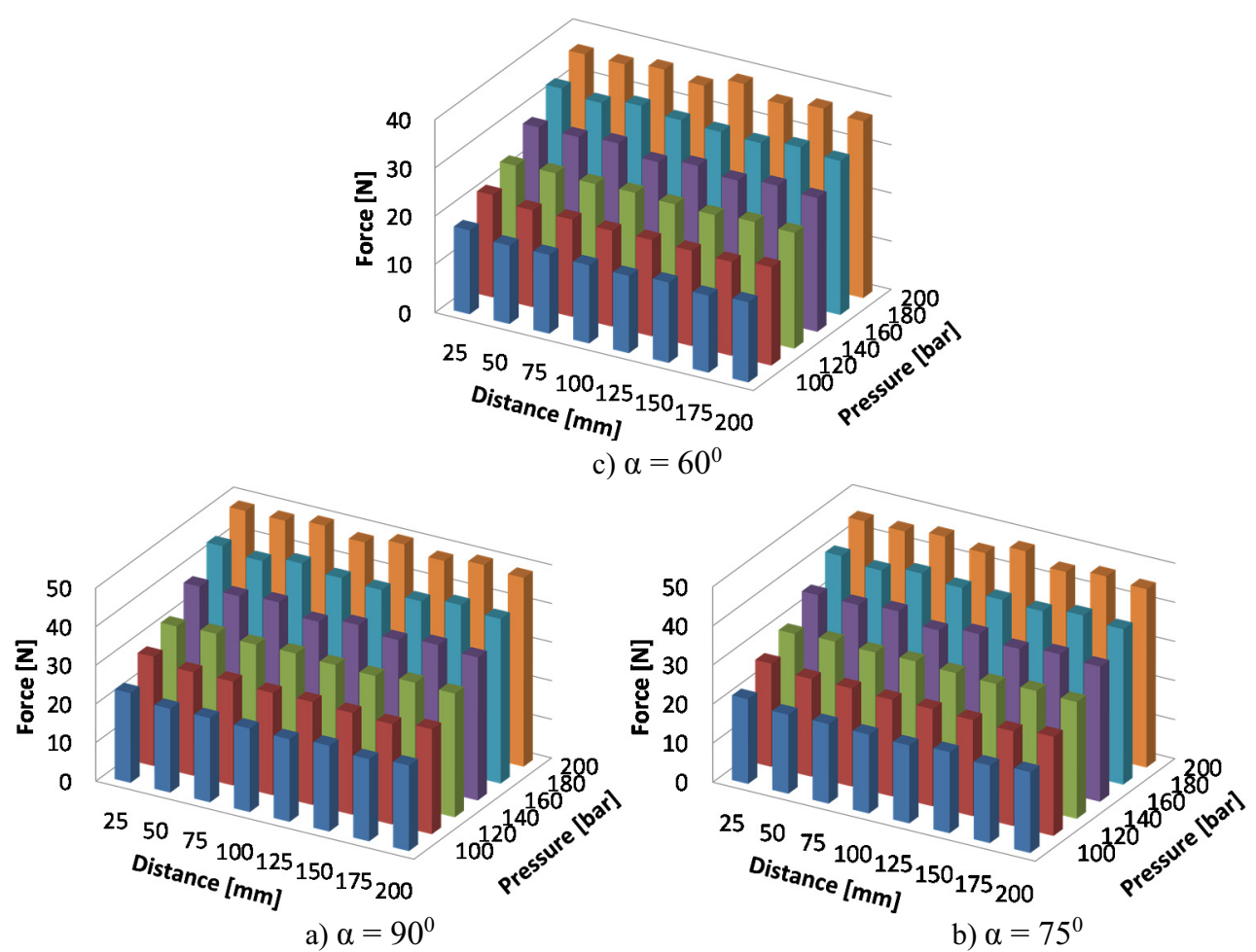

Fig. 6. Values of impact forces for nozzle diameter $\mathrm{D}=1.5 \mathrm{~mm}$ for different values of impact angle $\alpha$. 


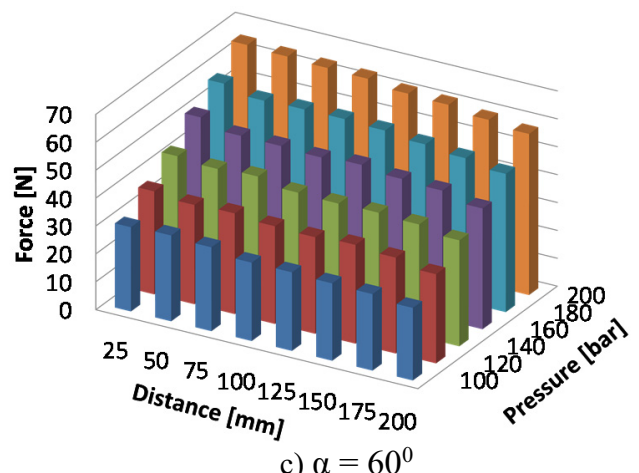

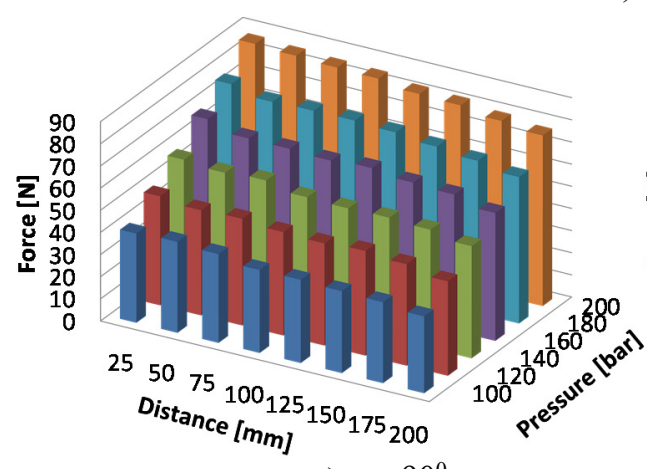

a) $\alpha=90^{\circ}$

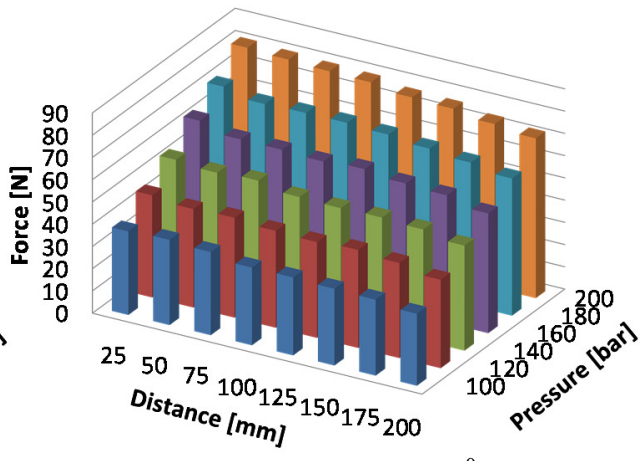

b) $\alpha=75^{0}$

Fig. 7. Values of impact forces for nozzle diameter $\mathrm{D}=2 \mathrm{~mm}$ for different values of impact angle $\alpha$.

\subsection{Determining the Influence of the process parameters}

Using the Full factorial method has conducted an analysis of the variance to determine the contribution of each parameter and their interactions on the impact force. Table 2 presents the analysis of the variance, using Minitab 17.

Table 2. Analysis of Variance (Minitab 17).

\begin{tabular}{|c|c|c|c|}
\hline Source & $\begin{array}{c}\text { DF } \\
\text { (degree of freedom) }\end{array}$ & $\begin{array}{c}\text { Seq. SS } \\
\text { (sum of square) }\end{array}$ & Contribution \\
\hline Model & 103 & 163,747 & $99.87 \%$ \\
\hline Linear & 16 & 153,677 & $93.73 \%$ \\
\hline Diameter & 2 & 117,239 & $71.50 \%$ \\
\hline Pressure & 5 & 29,641 & $18.08 \%$ \\
\hline Distance & 7 & 410 & $0.25 \%$ \\
\hline Angle & 2 & 6,387 & $3.90 \%$ \\
\hline 2-Way Interactions & 87 & 10,070 & $6.14 \%$ \\
\hline Diameter*Pressure & 10 & 7,626 & $4.65 \%$ \\
\hline Diameter*Distance & 14 & 333 & $0.20 \%$ \\
\hline Diamete**Angle & 4 & 1,636 & $1.00 \%$ \\
\hline Pressure*Distance & 35 & 55 & $0.03 \%$ \\
\hline Pressure*Angle & 10 & 414 & $0.25 \%$ \\
\hline Distance*Angle & 14 & 6 & $0.00 \%$ \\
\hline Error & 328 & 217 & $0.13 \%$ \\
\hline Total & 431 & 163,965 & $100.00 \%$ \\
\hline
\end{tabular}




\section{Conclusions}

In this paper is presented an experimental research methodology, which uses full factorial method. This allows determining the influence of process parameters to impact forces produced by water jets.

In order to measure the impact forces between the water jet and a flat and rigid surface, a stand was designed and built for generating pressure water jets, as well as a device to measure the impact forces.

Based on the results of experimental work presented in this paper it was determined that the contribution of the process parameters and their interactions are, as follows:

-The most important parameter is the diameter of the nozzle, with a percentage of influence of $71.50 \%$;

-The second parameter is the pressure of water jet, with a percentage of $18.08 \%$;

-The third parameter is the impact angle, with a percentage of $3.90 \%$;

-The distance parameter, with a percentage of $0.25 \%$ is virtually insignificant;

-Between interactions only diameter and pressure have an important contribution $4.65 \%$;

-All other interactions have a low importance (from $1 \%$ to $0 \%$ ).

For the experimental domain defined, only three of the four parameters have influence on impact forces. Distance $\mathrm{x}$ has an influence only $0.25 \%$, so maybe neglected.

\section{References}

1. W. F. Adler, The Mechanics of Liquid Impact. Treatise on Materials Science and Technology ( Ney York: Academic, 1979)

2. S. J. Leach, G. L. Walker, Some Aspects of Rock cutting by High Speed Water Jets. Philosophical Transactions of the Royal Society of London, 260, 295-308 (1966)

3. M. Leu, C.P. Meng, E.S. Geskin, L. Tismeneskiy, Mathematical modelling and experimental verification of stationary waterjet cleaning process, ASME Journal of Manufacturing Science and Engineering, 120, 571-579 (1998)

4. A. Guha, R.M. Barron, R. Balachandar, An Experimental and Numerical Study of Water Jet Cleaning Process, Journal of Materials Processing Technology, 610-618 (2011)

5. M. Annoni, L. Cristaldi, M. Faifer, M. Norgia, Orifice Coefficients Evaluation for Water Jet Application, 16th IMECO TC4 Symposium, 125-130 (2008)

6. E. Ghassemieh, H.K. Versteeg, M. Acar, The effect of nozzle geometry on the flow characteristics of small water jet, Proceedings of the Institution of Mechanical Engineers - Part C, 220 (2006)

7. Y. Liu, F. Ma, H. Xie, Y. Li, Development of Impact Test System for Waterjet Descaling Nozzles with LabVIEW, International Conference in Web Information Systems and Mining, 1 (2010)

8. A. W. Momber, Hydroblasting and Coating of Stell structures (Oxford Elsevier Ltd, 2003)

9. D.C. Montgomery, Design and analysis of experiments (Wiley, 2013)

10. N. Medan, Research and Contributions to the Functioning of Cleaning Head-Sewer System ( PhD Thesis, Baia Mare, 2014) 